\title{
Resilience and sustainability of supply chain management in the Indian automobile industry
}

\author{
Sachin B. Khot ${ }^{\mathrm{a}^{*}}$ and S. Thiagarajan ${ }^{\mathrm{b}}$
}

a PhD Scholar, School of Mechanical Engineering, Vellore Institute of Technology, Vellore, India ${ }^{b}$ Professor, School of Mechanical Engineering, Vellore Institute of Technology, Vellore, India

\section{H R O N I C L E}

Article history:

Received: January 30, 2019

Received in revised format: April

20, 2019

Accepted: April 22, 2019

Available online:

April 24, 2019

Keywords:

Supply Chain

Sustainability

Resilience

Automobile Sector

DEMATEL

\section{A B S T R A C T}

\begin{abstract}
Supply chain provides continual turbulence with unpredictable disruptions potential for enterprises with complex network infrastructure. Supply chain in enterprises needs to be resilient and sustainable to provide effective response, removing vulnerabilities and minimizing the impact of negative disturbances. This review article is based on evaluating the role of supply chain management in automobile sector of India. The overall findings derived from review of refined articles state that, in countries like India, automobile industry needs to have appropriate management commitment for sustainability and resilience of supply chain rather than rules and regulations of government. The review article examined 914 articles related to evaluating supply chain management practices in automobile sector of India. Through the analysis of the collected articles, it is evident that DEMATEL is effective technique for providing inter-relationship in automobile industry in India. Rather than economic influence in automobile sector, managerial activity is a major concern for effective sustainable and resilience practices in automobile industry of India.
\end{abstract}

\section{Introduction}

Supply chain (SC) provides continual turbulence with unpredictable disruptions potential for enterprises with complex network infrastructure (Pettit et al., 2010). SC implementation in enterprises influence on normal operations, increase in frequency number, stability and commitments. SC needs to be resilient in enterprises to provide effective response, removing vulnerabilities and minimizing the impact of negative disturbances in an organization (Carvalho et al., 2012). Many organizations have understood the importance of investment in sustainability strategy. To achieve desire effective and informed decision in an organization decision-support tools and analytical models have been developed for effective functioning of enterprises. Over two decades, management and designing of substantial design and management draw attention of academic researchers (Brandenburg et al., 2014; Fahimnia et al., 2015; Seuring, 2013). In early 2000s, Sustainable Supply Chain Management (SSCM) has drawn attention for both industry and 
academia field (Jia et al., 2018). As a result, this factors motivates significant growing attention for literature related to SC resilience (Scavarda et al., 2015). SC professionals have widely examined sustainability practices for environmental, social and economic goals with SC planning and designing. The effort on examining SC sustainability concentrates predominantly on minimizing burden to environment which is commonly measured as resource consumption and greenhouse gas (GHG) (Boukherroub et al., 2015; Fahimnia et al., 2015a,b).

$\mathrm{SC}$ resilience in enterprises offers capacity for retain and disturbances of SC to retain basic function and disruptions structure (Jabbarzadeh et al., 2014; Pettit et al., 2010). Implementation of SC in enterprises reduces the risk of the absent of the contingency plan (Cutter, 2014; Fahimnia \& Jabbarzadeh, 2016). In human life, day-to-day activity highly relies on automobile industry as a major key driver due to ease of mobility. It does not offer only mobility but provides desire impact on global industries in terms of social, economic and environmental factor (Xia et al., 2015). In arguable manner automobile sector faces higher environmental challenges in worldwide which is responsible for air quality deterioration, global warming and lack of automobile product handling. Automobile industry has forced to shifted towards specific sustainability practices due to governmental globalization and environmental challenges (Govindan et al., 2015a,b). SC practices in automobile industry reverse adverse effect of industry with social benefits and environmental friendly approach for increasing profitability of organization. Global economy largely relies on automobile industry for growth and development of particular nation economy. In simple term automobile is denoted as 'both a form and function' product based factor with involvement of high level engineering and positioned with fashion product (Technology Evaluation Centers, 2018). Due to wider contribution of automobile it is defined as "the industry of industries" since it provides the outcome which is similar to manufacturing sectors and supports upstream and downstream industries with product output such as steel, mining, finance, insurance and market (AT Kearney, 2013; Bhattacharya et al., 2014). Indian economy highly relies on automobile industry as major contributor. As per AMP 2026 Auto Tech Review report it is estimated that automobile industry will incorporate $12 \%$ of overall country GDP. Similar to global automobile sector Indian automotive sector also faces peak globalization pressure, social customers, government rules and regulation, standards and social awareness motivated implementation of SC practices in automobile sector due to increase in Social and environmental issues (Kannan et al., 2016). Indian automobile industries are targeted effectively on SC practices with increased sustainable practices (Thanki et al., 2016).

Automobile industry with supply chain management facilitates product production at higher rate and increase in innovation rate draws prominent source for research in automobile industry. In India, automobile industry comprises four process such as dealers, service centers, auto component suppliers (OEMs) and automobile manufacturers. This process specifically contributed for four distinct vehicles such as cars, commercial vehicles, special purpose vehicles and two wheelers. Automobile industry in India experienced significant growth in recent years due to entry of automobile giants such as Ford, Nissan, Volkswagen, General Motors, Toyota and Honda. The automobile industries contribute fierce market competition with other major automobile industries such as Mahindra \& Mahindra, Ashok Leyland, Maruti, Hyundai, Bajaj and Tata motors. Even though Indian automobile industry is subjected to higher foreign direct investment (FDI) with effective inflow of US\$ 7,518 million from April 2000 to November 2012 this contributes only about $4 \%$ of consolidated FDI inflow in country. The increase in FDI inflow is due to contribution of big players in Indian automobile sector like Volvo, Jaguar, Audi, and BMW with expected growth and development in selected sector (Pareek et al., 2013).

Indian automobile industries adopt the sustainability concept in their supply chain process to withstand competitiveness and to offer competitive edge with other automobile industry (Bouzon et al., 2016). In conventional researches implementation practices in automobile industries has been examined from distinct perspective point but none of the research offers more prominent practices. In India, automobile industry conquers desirable economic development but existing research do not provid any inter influence practices in organization for supply chain management (Mathivathanan et al., 2018; Silvestre et al., 
2018). This review article aimed to investigate the critical factors involved in supply chain management practices for sustainability and resilience of supply chain management in automobile industry in India.

\section{Research Questions}

In India, automotive industries face with distinct number of questions due to phenomenal impact of awareness about environment, globalization and modernization (Zailani et al., 2017). This impact in automobile sector of India leads to several questions as follows:

1. How does particular automobile organization transform supply chain management in sustainable one?

2. How to retain effective competitive market without compromising automobile sector environment and social aspects in India?

3. How to achieve higher environmental and social performance?

4. What is effective approach for particular automobile enterprises to withstand market trends of foreign investors in Indian automobile sector?

The answers to all above questions are associated with the adoption of sustainable supply chain practices in automobile sector of India. According to Markman and Krause (2016), sustainable practices in an organization should adopt two inseparable principles as stated: The organization needs to improve vitality of economy, standards and ecological health of organization and also needs to prioritize different factors in order such as environment, society and economy. In the area of sustainable and resilience supply chain management there have been significant growth in the number of studies carried out (Beske et al., 2014). Carter and Rogers (2008) developed a framework for SSCM supply chain practices and also presented pre-requisites for the implementation of SSCM practices with appropriate case study. Another research by Carter and Rogers (2008) examined barriers involved in the implementation of resilience supply chain practices in organization. Findings of this research have concluded that the lack of appropriate managerial time is a major drawback for implementing SSCM in India rather than financial resources of organization. To facilitate the implementation of SSCM practices in Indian organization Svensson (2007) classified supply chain in some orders through practical implementation. Pagell and Wu (2009) and Ageron et al. (2012) proposed a case study model and conceptual model for evaluating unique characteristics of SSCM practices. The conceptual model provides desire characteristics of SSCM practices and barriers in adoption of SSCM in organizations were evaluated to achieve market competitive advantages. Further critical analysis of the existing literature's framework was presented by Beske (2012) who developed a framework which integrates dynamic capability and SSCM practices implementation in organization. A research by Vachon and Klassen (2008) presented distinct factors involved in collaboration activity involved in upstream and downstream SSCM practices in Indian organization in supply chain partners. To withstand sustainable practices Chkanikova (2012) stated that to implement SSCM practices an automobile firm should possess internal resources of organization.

\section{Literature Review}

\subsection{Sustainable Supply Chain Management (SSCM)}

The area of SSCM research has witnessed exponential growth during the past several years as is indicated with a substantial increment in the quantum of publications within this domain (Seuring \& Müller, 2008). Research articles in excess of 300 were published during the past 15 years that covered topics such as green and sustainable supply chain management (Seuring, 2013). The primary efforts lay stress on enhancing supply chains economic facets which was succeeded with the introduction of green/environmental practices within supply chains and thus leading to an evolution within green supply chain management (Kannan Govindan et al., 2015). According to Srivastava (2007), green supply chain management is related to incorporating environmental aspects within supply chain management. It also comprised of 
material selection and sourcing, design of product, end-of-life management and delivering the end-product to consumers. Therefore, the focus of green supply chain is largely on ensuring sustainability within the supply chain and the relevant advantages it brings (Zhu \& Sarkis, 2004). Globalization as a concept and the advent of corporate social responsibilities stimulated those social aspects be taken into account with regards to environmental concerns (Kannan Govindan et al., 2014). When supply chain management equally integrates sustainability's three pillars viz., society, economy and environment, it is when the term SSCM comes into play (Elkington, 1998).

\subsection{Resilience and Sustainability}

In recent times, issues pertaining to sustainability and resilience within supply chains particularly in the automotive sector have assumed much significance in terms of research. Hence, it is imperative to understand the concepts related to sustainability and resilience from this specific context. In recent years, sustainable supply chain management provides remarkable growth which motivates researchers and consequences on number of publications drastically (Ouabouch, 2015). In supply chain, risk management of automobile sector supply chain resilience is considered a critical factor (Ponis \& Koronis, 2012; Ponomarov \& Holcomb, 2009). Generally, resilience is defined as "the capacity for continuous construction" (Laroche et al., n.d.). Through review of the existing literature presented several terms and explanation for supply chain management have been presented as follows: "Supply chain management is system ability to operates in original state else it provides moving to new operational state after disturbed from desire operational state" (Ponomarov \& Holcomb, 2009). "resilience represents the ability of a material to recover its original shape following a deformation" (Michelman, 2007). "Resilience supply chain management implemented in organization for managing unexpected events, operation and recovery of continuity maintenance and response to disruptions at desire level for structure and functional control in organization" (Ponomarov \& Holcomb, 2009).

\section{Table 1}

Sustainable SSCM Practices

\begin{tabular}{ll}
\hline Author & SSCM Practices \\
\hline Beske et al. (2014) & Strategic orientation, Continuity, Collaboration, Risk Management, Proactivity \\
Carter \& Rogers (2008) & Risk Management, Proactivity, Transparency, \\
Svensson, G. (2007) & Lifecycle Assessment, Environmental Management, \\
Pagell and Wu (2009) & GSCM, Continuity, Strategic Orientation, Risk Management, Collaboration, Traceability \\
Ageron et al. (2012) & Proactivity, Collaboration, Risk Management \\
Beske, P. (2012) & Orientation, Continuity, Risk Management, Collaboration \\
Vachon and Klassen (2008) & Environmental Collaboration, SCM Collaboration \\
Chkanikova (2012) & Triple Bottom Line Assessment, Collaboration, Continuity \\
Suering and Miller (2008) & Lifecycle Assessment \\
Seuring (2013) & Lifecycle Assessment \\
Srivastava (2007) & Proactivity, Lifecycle Assessment \\
Zhu \& Sarkis (2004) & Internal environment management, External GSCM, Eco-Design \\
Elkington (1998) & Triple Bottom Line Assessment \\
\hline
\end{tabular}

Hohenstein et al. (2015) presented systematic review about supply chain resilience. This review concentrated on SC resilience conceptualization with different phases such as recovery, growth, readiness and response. Through analysis of this article 67 publications from 2003 to 2013 have been discovered. In 2016, Kamalahmadi and Parast (2016) evaluated total 100 publications related to SC resilience in automobile sector from 2000 to 2014 . Further, this review article developed a framework related to supply chain resilience by considering recovery, response, anticipation and resistance with creation of "Supply Chain Resilience Principles". Development of resilience supply chain framework considered supply chain reality, operational strategy of organization, decision level and present complex scenarios in supply chain with aim of resilient operation in automobile organization. Through in-depth analysis, classification between uncertainty and risk factors in selected organization was presented. Uncertainty was also 
presented as unpredictable events or unknown risks (Wang \& Xiao, 2016). Systematic review of literature presented by Wang and Xiao (2016) evaluated 48 publications from 1996 to 2009. This review provides SC resilience emphasis on organization through design and organization. Network design of supply chain provides economic development with several intricate relationship factors of supply chain. This research defines supply chain as "a set of SC that are independent". Further this research provides resilience and sustainable supply chain management publication has been increased since 2003 with outsourcing risk of susceptible risks (Kamalahmadi \& Parast, 2016).

Table 2

Resilience Strategies and Factors Impacting Resilience

\begin{tabular}{lll}
\hline Author & Resilience Strategies & Factors Impacting Resilience \\
\hline Ouabouch (2015) & $\begin{array}{l}\text { Creating \& Increasing Redundancies, Building } \\
\text { Flexibility, Changing Corporate Culture }\end{array}$ & $\begin{array}{l}\text { SC Visibility, Information Sharing, Supply Chain Agility, } \\
\text { Collaboration, Risk \& Revenue Sharing, SC Structure }\end{array}$ \\
Ponis and Koronis (2012) & $\begin{array}{l}\text { Increasing Redundancy, Building Flexibility, } \\
\text { Changing Corporate Culture }\end{array}$ & $\begin{array}{l}\text { Collaborative Supplier Base Strategy, Information Sharing, } \\
\text { Risk Management, Understanding SC Network, Applying } \\
\text { Reengineering Practices, }\end{array}$ \\
Ponomarov et al. (2009). & Flexibility, Increasing Redundancy, & Reengineering Practices, Information Sharing, Collaboration \\
Laroche et al. (n.d.) & $\begin{array}{l}\text { Changing Corporate Culture, Building Flexibil- } \\
\text { ity, Increasing Redundancy }\end{array}$ & $\begin{array}{l}\text { Information Sharing, Reengineering Practices, Collaborative } \\
\text { Supplier Base Strategy }\end{array}$ \\
Michelman (2007) & $\begin{array}{l}\text { Building Flexibility, Changing Corporate Cul- } \\
\text { ture, Increasing Redundancy }\end{array}$ & Reengineering Practices, SC Visibility, Information Sharing, \\
Hohenstein et al. (2015) & Flexibility, Redundancy, Collaboration & \\
Kamalahmadi \& Parast (2016) & Flexibility, Redundancy, Leadership, Innovation & \\
\hline
\end{tabular}

\section{Methodology}

The initial step is to identify practices that are common within SSCM practices on the basis of a literature review. Subsequently, an analysis of the SSCM practices would be executed from the perspective of multiple stakeholders. From the literature, the SSCM practices would be evaluated with the help of the Decision-Making Trial and Evaluation Laboratory (DEMATEL) tool (Fontela \& Gabus, 1974). The SSCM practices within groups of stakeholders would be analyzed to recognize any variations or similarities within the group. The methodology for the solution that will be applied in order to identify any interinfluences and prominence within SSCM practices would be DEMATEL which is a Multi-Criteria Decision Making (MCDM) tool. The tool would analyze any inter-influences between intricate criterions (Jia et al., 2015) particularly when there is simplification in terms of challenges and at the same time it also provides a map of interrelationships.

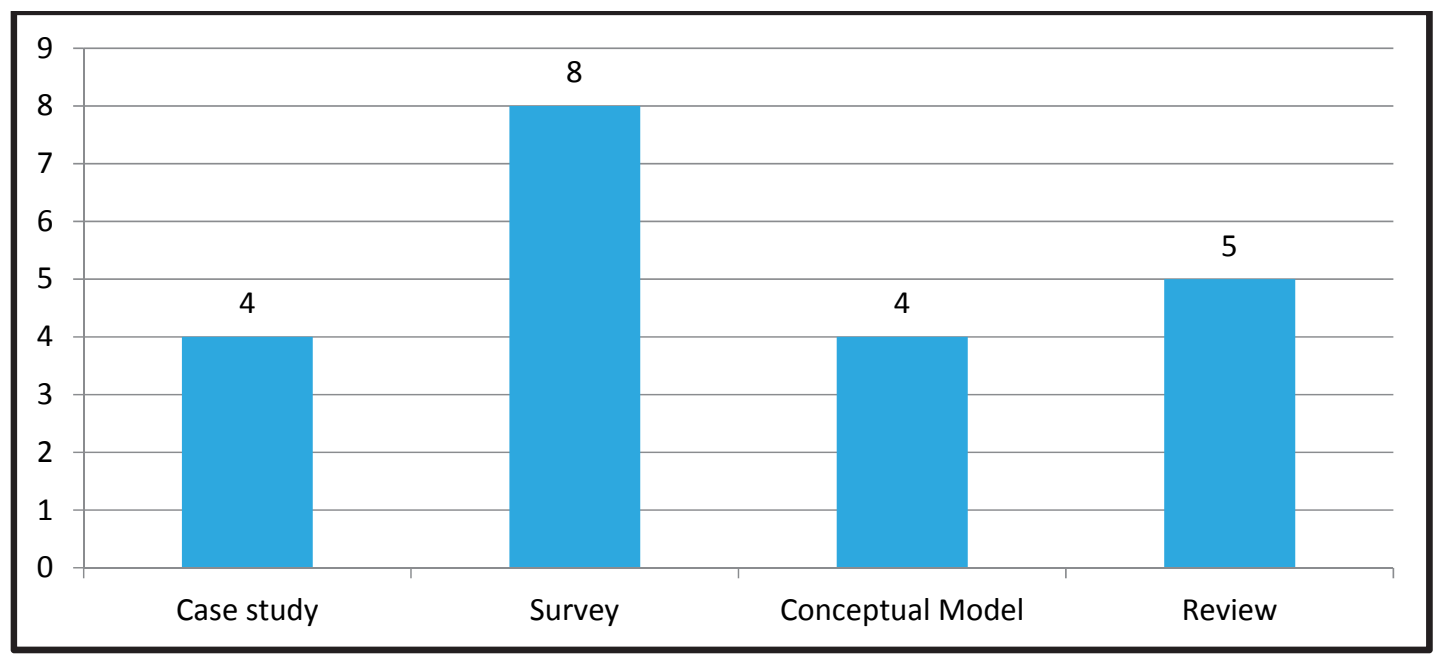

Fig. 1. Research methodologies employed 


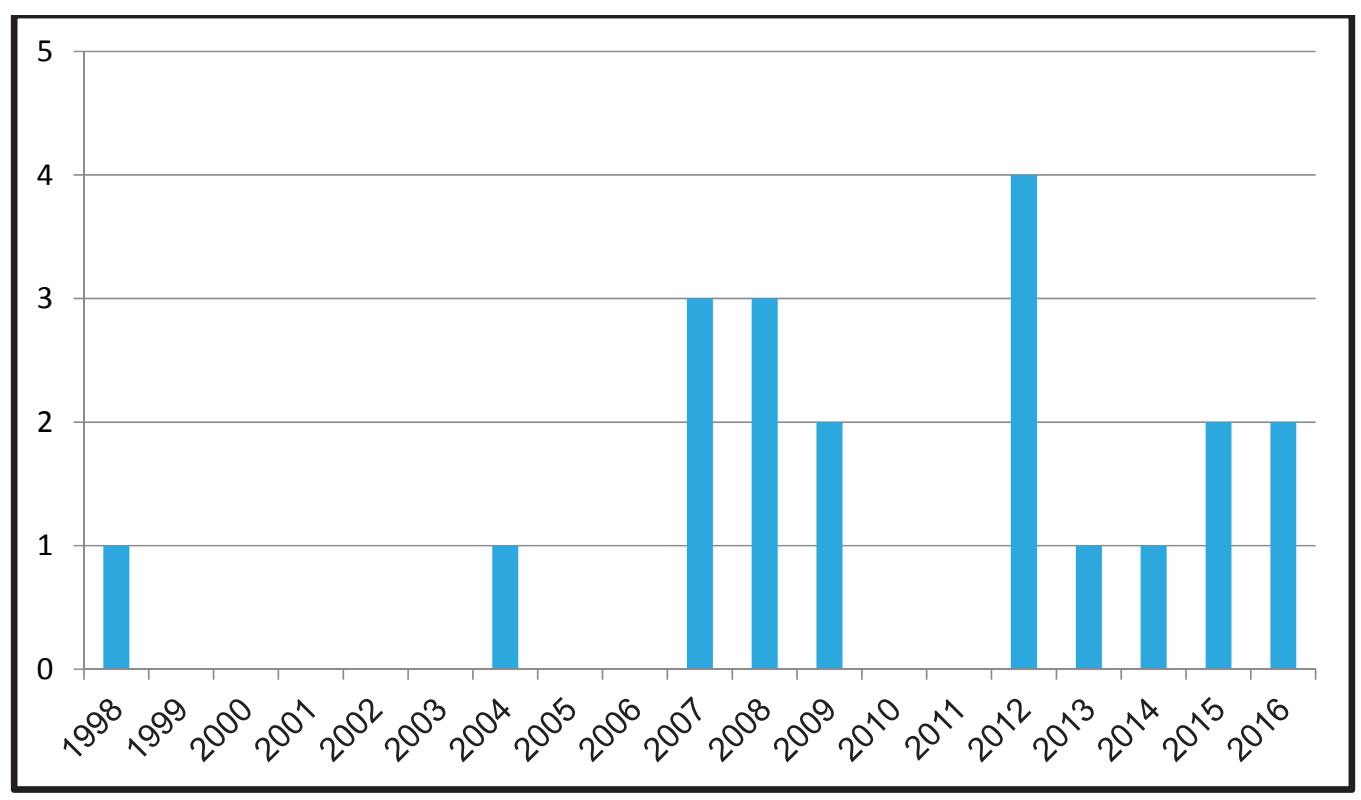

Fig. 2. Time Distribution Graph

\section{Discussion}

The review of articles have clearly stated that sustainable and resilience practices are appropriate for automotive industries in order to achieve sustainability. Majority of research topics focused on sustainability practices and other metrics considered in literature for SSCM practices in automobile industries are pressure from stakeholders, leadership, government policies, and environmental factors. For supply chain practices resilience and sustainability in an automobile industry quantitative model and decision theory is considered as effective parameter. The review of the research articles published in Journal "Resources, Conservation and Recycling" concentrated on government policies and regulations adopted for SSCM practices in India. Further, this journal published many articles related to supply chain practices in Indian Automobile sector. In "International Journal of Production Economics" many articles focused on examining green house impact of automobile industry. Sustainability of supply chain practices in automobile sector are widely presented in "Journal of Cleaner Production" which includes different techniques and method for effective SSCM. Resilience of supply chain process in India has been widely published in "International Journal of Production Economics" and the journal offers theoretical framework for resilience in India supply chain process. Other journals such as "Journal of Cleaner Production", "Science of The Total Environment", "International Journal of Production Economics" offer supply chain resilience in India. To adopt sustainable supply chain management practices identification of prominent practices in automobile supply chain is prominent but due to influence of other practices it is difficult to identify. Through the analysis of conventional research process DEMATEL has been widely utilized for inter relationship practices. This process effectively was involved in offering relationship criteria of influencing and influenced practices in organization.

\section{Analyzed Framework}

To examine cause and relationship between resilience and sustainable practices in automobile sector in India existing research considered DEMATEL approach for evaluation (Yang et al., 2007). Through DEMATEL 25 supply chain practices were analyzed in automotive industries of India for achieving effective sustainable supply chain practices to gain effective competitive advantages with other firm. With review of existing literature articles it has been observed that the implementation of effective supply 
chain practices in automobile industry is complex due to government rules and regulations. To incorporate positive supply chain practices in automobile sector of India it is necessary to adopt effective sustainable supply chain practices. Through DEMATEL 25, practices were studied in point of multi stakeholder perspectives in automobile industry of India. Collaboration with stakeholders has been incorporated with global elements to profound between success of sustainability and stakeholder perspectives (McComb et al., 2017). Due to complexity of data collection and only existing research targeted qualitative, the necessary data were collected from survey of questionnaire from relevant field of study in south India. Those researches exploited view in social stakeholders' point of view, government policies and management activities of automobile industry. In automobile industry stakeholders with various preferences were examined with different perspective parameters at top management. The review of articles stated that in India, automobile industry with prominent sustainable and resilience supply chain management triple bottom line approach need to be adopted with desire management commitment and orientation of supply chain practices. The factors will directly impact on remaining practices adopted by automobile industry in India. In simple term it can be defined as improvement in cause group directly impact on effect group easily (Falatoonitoosi et al., 2013). Hence adoption of prominent practices in automobile industry will provide better sustainability practices in automobile industry. Automobile sector have top practices in organization related to top-management which combines stakeholders perspectives of organization. The overall findings derived from a review of refined articles have stated that in countries like India automobile industry needs to have appropriate management commitment for sustainable and resilience of supply chain rather than rules and regulations of government. Automobile industry relies on private sector for effective implementation of rules and regulations posed by government which can be applicable to public automobile sectors. Generally, in India the majority of automobile industries are privately owned organizations hence this statement is applicable to all automobile industries in India (Mathivathanan et al., 2018).

\section{Conclusion}

Sustainability in automobile industry of India was achieved with supply chain management practices. Developed nations are able to adopt sustainable practices in organizations through government regulations and policies stringent while in case of developing nations it is difficult to implement such policy. This is due to difficulty in identifying prominent practices and influence over other practices for the implementation of SSCM practices. Once those effective implementation practices in supply chain have been identified, the related practices in automobile firm perform effectively. Hence this review articles examined 914 articles related to evaluating supply chain management practices in automobile sector of India. Through the analysis of collected articles it was evident that DEMATEL is effective technique for providing inter-relationship in automobile industry in India. Rather than economic influence in automobile sector, managerial activity is a major concern for effective sustainable and resilience practices in automobile industry of India. This article concentrates sustainable and resilience of supply chain practices in automobile industries of India alone. In future, this study can be extended to other industries or sectors such as service, food, etc. Even by considering diverse scenario, this research can be conducted with the consideration of diverse environment which offers better insights towards organizational culture.

\section{References}

Ageron, B., Gunasekaran, A., \& Spalanzani, A. (2012). Sustainable supply management: An empirical study. International Journal of Production Economics, 140(1), 168-182.

AT Kearney. (2013). The Contribution of the Automobile Industry to Technology and Value Creation. Retrieved October 3, 2018, from https://www.atkearney.in/documents/10192/2426917/ The + Contribution + of + the + Automobile + Industry + to + Technology + and + Value + Creation.pdf $/ 8$ a $5 f 53$ b4-4bd2-42cc-8e2e-82a0872aa429

Beske, P. (2012). Dynamic capabilities and sustainable supply chain management. International Journal of Physical Distribution \& Logistics Management, 42(4), 372-387. 
Beske, P., Land, A., \& Seuring, S. (2014). Sustainable supply chain management practices and dynamic capabilities in the food industry: A critical analysis of the literature. International Journal of Production Economics, 152, 131-143.

Bhattacharya, S., Mukhopadhyay, D., \& Giri, S. (2014). Supply Chain Management in Indian Automotive Industry : Complexities, Challenges and Way Ahead. International Journal of Managing Value and Supply Chains, 5(2), 49-62.

Boukherroub, T., Ruiz, A., Guinet, A., \& Fondrevelle, J. (2015). An integrated approach for sustainable supply chain planning. Computers \& Operations Research, 54, 180-194.

Bouzon, M., Govindan, K., Rodriguez, C. M. T., \& Campos, L. M. S. (2016). Identification and analysis of reverse logistics barriers using fuzzy Delphi method and AHP. Resources, Conservation and Recycling, 108, 182-197.

Brandenburg, M., Govindan, K., Sarkis, J., \& Seuring, S. (2014). Quantitative models for sustainable supply chain management: Developments and directions. European Journal of Operational Research, 233(2), 299-312.

Carter, C. R., \& Rogers, D. S. (2008). A framework of sustainable supply chain management: moving toward new theory. International Journal of Physical Distribution and Logistics Management, 38(5), $360-387$.

Carvalho, H., Barroso, A. P., Machado, V. H., Azevedo, S., \& Cruz-Machado, V. (2012). Supply chain redesign for resilience using simulation. Computers \& Industrial Engineering, 62(1), 329-341.

Chkanikova, O. (2012). Sustainable supply chain management: theoretical literature overview. Sweden.

Cutter, S. L. (2014). Building Disaster Resilience: Steps toward Sustainability. Challenges in Sustainability, 1(2).

Elkington, J. (1998). Partnerships fromcannibals with forks: The triple bottom line of 21 st-century business. Environmental Quality Management, 8(1), 37-51.

Fahimnia, B., \& Jabbarzadeh, A. (2016). Marrying supply chain sustainability and resilience: A match made in heaven. Transportation Research Part E: Logistics and Transportation Review, 91, 306-324.

Fahimnia, B., Sarkis, J., \& Davarzani, H. (2015a). Green supply chain management: A review and bibliometric analysis. International Journal of Production Economics, 162, 101-114.

Fahimnia, B., Sarkis, J., \& Eshragh, A. (2015b). A tradeoff model for green supply chain planning:A leanness-versus-greenness analysis. Omega, 54, 173-190.

Falatoonitoosi, E., Leman, Z., Sorooshian, S., \& Salimi, M. (2013). Decision-Making Trial and Evaluation Laboratory. Research Journal of Applied Sciences, Engineering and Technology, 5(13), 3476-3480.

Fontela, E., \& Gabus, A. (1974). DEMATEL: Progress achieved.

Govindan, K., Azevedo, S. G., Carvalho, H., \& Cruz-Machado, V. (2015a). Lean, green and resilient practices influence on supply chain performance: interpretive structural modeling approach. International Journal of Environmental Science and Technology, 12(1), 15-34.

Govindan, K., Soleimani, H., \& Kannan, D. (2015b). Reverse logistics and closed-loop supply chain: A comprehensive review to explore the future. European Journal of Operational Research, 240(3), 603626.

Govindan, K., Kannan, D., \& Shankar, K. M. (2014). Evaluating the drivers of corporate social responsibility in the mining industry with multi-criteria approach: A multi-stakeholder perspective. Journal of Cleaner Production, 84, 214-232.

Hohenstein, N.-O., Feisel, E., Hartmann, E., \& Giunipero, L. (2015). Research on the phenomenon of supply chain resilience. International Journal of Physical Distribution \& Logistics Management, 45(1/2), 90-117.

Jabbarzadeh, A., Fahimnia, B., \& Seuring, S. (2014). Dynamic supply chain network design for the supply of blood in disasters: A robust model with real world application. Transportation Research Part E: Logistics and Transportation Review, 70, 225-244.

Jia, F., Gong, Y., \& Brown, S. (2018). Multi-tier sustainable supply chain management: The role of supply chain leadership. International Journal of Production Economics. https://doi.org/10.1016/j.jpe.2018.07.022 Jia, P., Govindan, K., \& Kannan, D. (2015). Identification and evaluation of influential criteria for the 
selection of an environmental shipping carrier using DEMATEL: a case from India. International Journal of Shipping and Transport Logistics, 7(6), 719.

Kamalahmadi, M., \& Parast, M. M. (2016). A review of the literature on the principles of enterprise and supply chain resilience: Major findings and directions for future research. International Journal of Production Economics, 171, 116-133.

Kannan, D., Govindan, K., \& Shankar, M. (2016). India: Formalize recycling of electronic waste. Nature, 530(7590), 281.

Laroche, H., Journé, B., \& Hollnagel, E. (n.d.). Dependability and Resilience as Dimensions of Organizational Performance. Retrieved October 3, 2018, from https:/www.cairn-int.info/articleE_MANA_124_0224--dependability-and-resilience-as.htm

Markman, G. D., \& Krause, D. (2016). Theory Building Surrounding Sustainable Supply Chain Management: Assessing What We Know, Exploring Where to Go. Journal of Supply Chain Management. Retrieved from https:/www.questia.com/read/1G1-451531003/theory-buildingsurrounding-sustainable-supply-chain

Mathivathanan, D., Kannan, D., \& Haq, A. N. (2018). Sustainable supply chain management practices in Indian automotive industry: A multi-stakeholder view. Resources, Conservation and Recycling, $128,284-305$.

McComb, E. J., Boyd, S., \& Boluk, K. (2017). Stakeholder collaboration: A means to the success of rural tourism destinations? A critical evaluation of the existence of stakeholder collaboration within the Mournes, Northern Ireland. Tourism and Hospitality Research, 17(3), 286-297.

Michelman, P. (2007). Building a Resilient Supply Chain. Retrieved October 3, 2018, from https://hbr.org/2007/08/building-a-resilient-supply-ch

Ouabouch, L. (2015). Overview on Supply Chain Resilience. Retrieved October 3, 2018, from https://www.researchgate.net/publication/277597871_Overview_on_Supply_Chain_Resilience

Pagell, M., \& Wu, Z. (2009). Building A More Complete Theory Of Sustainable Supply Chain Management Using Case Studies Of 10 Exemplars. Journal of Supply Chain Management, 45(2), 3756.

Pareek, A., Rathore, A. P. S., \& Jain, R. (2013). Linkages influencing NPD-SCM alignment Evidence from Indian automotive industry. In 2013 IEEE International Conference on Industrial Engineering and Engineering Management (pp. 541-545). IEEE. https://doi.org/10.1109/IEEM.2013.6962470

Pettit, T. J., Fiksel, J., \& Croxton, K. L. (2010). Ensuring Supply Chain Resilience: Development of a Conceptual Framework. Journal of Business Logistics, 31(1), 1-21.

Ponis, S. T., \& Koronis, E. (2012). Supply Chain Resilience: Definition Of Concept And Its Formative Elements. Journal of Applied Business Research (JABR), $28(5), 921$.

Ponomarov, S. Y., \& Holcomb, M. C. (2009). Understanding the concept of supply chain resilience. The International Journal of Logistics Management, 20(1), 124-143.

Scavarda, L. F., Ceryno, P. S., Pires, S., \& Klingebiel, K. (2015). Supply Chain Resilience Analysis: A Brazilian Automotive Case. Revista de Administração de Empresas, 55(3), 304-313.

Seuring, S. (2013). A review of modeling approaches for sustainable supply chain management. Decision Support Systems, 54(4), 1513-1520.

Seuring, S., \& Müller, M. (2008). From a literature review to a conceptual framework for sustainable supply chain management. Journal of Cleaner Production, 16(15), 1699-1710.

Silvestre, B. S., Monteiro, M. S., Viana, F. L. E., \& de Sousa-Filho, J. M. (2018). Challenges for sustainable supply chain management: When stakeholder collaboration becomes conducive to corruption. Journal of Cleaner Production, 194, 766-776.

Srivastava, S. K. (2007). Green supply-chain management: A state-of-the-art literature review. International Journal of Management Reviews, 9(1), 53-80.

Svensson, G. (2007). Aspects of sustainable supply chain management (SSCM): conceptual framework and empirical example. Supply Chain Management: An International Journal, 12(4), 262-266.

Technology Evaluation Centers. (2018). The Automotive Supply Chain in the New Normal: Analysis of the Industry and its Supply Chain Opportunities. Retrieved October 3, 2018, from https://www3.technologyevaluation.com/research/white-paper/the-automotive-supply-chain-in-the- 
new-normal-analysis-of-the-industry-and-its-supply-chain-opportunities.html

Thanki, S., Govindan, K., \& Thakkar, J. (2016). An investigation on lean-green implementation practices in Indian SMEs using analytical hierarchy process (AHP) approach. Journal of Cleaner Production, 135, 284-298.

Vachon, S., \& Klassen, R. D. (2008). Environmental management and manufacturing performance: The role of collaboration in the supply chain. International Journal of Production Economics, 111(2), 299-315.

Wang, Y., \& Xiao, R. (2016). An ant colony based resilience approach to cascading failures in cluster supply network. Physica A: Statistical Mechanics and Its Applications, 462, 150-166.

Xia, X., Govindan, K., \& Zhu, Q. (2015). Analyzing internal barriers for automotive parts remanufacturers in China using grey-DEMATEL approach. Journal of Cleaner Production, 87, 811825.

Yang, Y. O., Shieh, H., Leu, J., \& Tzen, G. (2007). A Novel Hybrid MCDM Model Combined with DEMATEL and ANP with Applications. Retrieved October 3, 2018, from http://citeseerx.ist.psu.edu/viewdoc/summary?doi=10.1.1.402.1382

Zailani, S., Govindan, K., Shaharudin, M. R., \& Kuan, E. E. L. (2017). Barriers to product return management in automotive manufacturing firms in Malaysia. Journal of Cleaner Production, 141, 22-40.

Zhu, Q., \& Sarkis, J. (2004). Relationships between operational practices and performance among early adopters of green supply chain management practices in Chinese manufacturing enterprises. Journal of Operations Management, 22(3), 265-289.

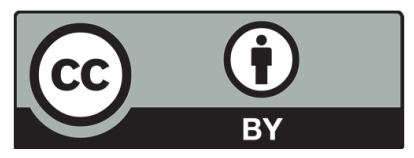

(C) 2019 by the authors; licensee Growing Science, Canada. This is an open access article distributed under the terms and conditions of the Creative Commons Attribution (CC-BY) license (http://creativecommons.org/licenses/by/4.0/). 